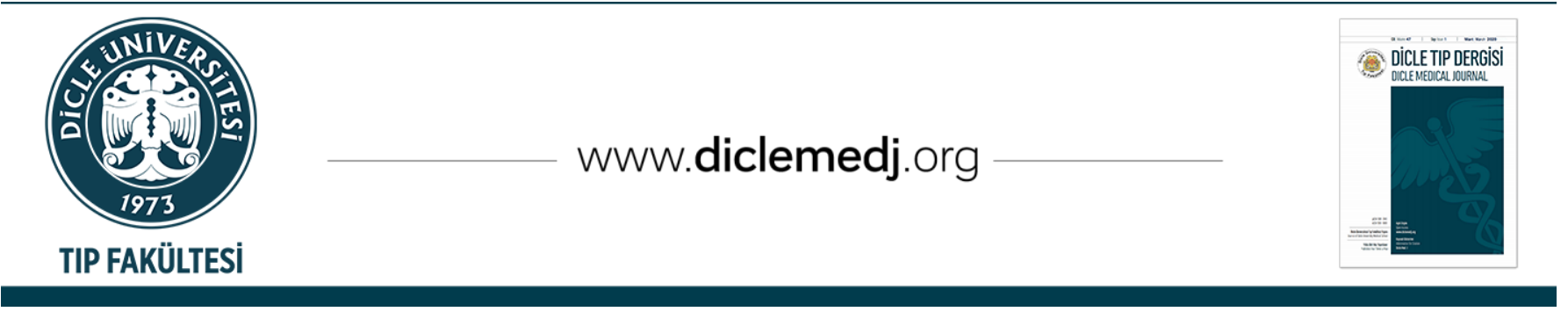

Özgün Araștırma / Original Article

\title{
CE2 Tipi Karaciğer Kist Hidatik Lezyonlarının Modifiye Kateterizasyon Yöntemi ile Tedavisinde 8 F ve 14 F Kateterlerin Kullanımının Karşılaştırılması
}

\author{
Bekir Turgut $\mathrm{iD} 1$ \\ 1 Konya Eğitim ve Araștırma Hastanesi, Sağllk Bilimleri Üniversitesi, Radyoloji ABD, Konya, Türkiye \\ Geliş: 03.02.2020; Revizyon: 02.04.2020; Kabul Tarihi: 06.04.2020
}

Öz

Amaç: Bu çalışmada CE2 karaciğer kist hidatik tedavisinde kullanılan modifiye kateterizasyon yönteminde kateter kalınlık seçiminin, etkinlik, rekürrens, komplikasyon ve hastane yatış süresi açısından karşılaştırılması amaçlandı.

Yöntemler: Ocak 2016 ve Ocak 2020 tarihleri arasında kurumda CE2 karaciğer kist hidatik tanılı ve modifiye kateterizasyon tedavisi uygulanmış olan hastaların verileri geriye dönük incelendi. Modifiye kateterizasyon yönteminde $8 \mathrm{~F}$ ve $14 \mathrm{~F}$ kateter kullanılan hastalar listelendi. Girişimsel radyolog tarafından tedavi öncesinde yapılmış olan USG raporları taranarak kist tipi, kist boyutu ve lokalizasyonu listelendi. Kayıtlı olan perkütan tedavi bilgileri ve raporları değerlendirilerek uygulanan tedavi türü, kullanılan kateter kalınlığı, komplikasyonlar, kateterizasyon süresi, hastanede yatış süresi listelendi. Takip USG raporları değerlendirilerek takip süresi, kistin son kontroldeki boyutu, uzun dönem nüks sonuçları ve nüks tedavi yöntemleri kayıt edildi. Her iki grupta bu listelenen değişkenler istatistik olarak kıyaslandı.

Bulgular: CE2 tipi kist hidatik nedeni ile modifiye kateterizasyon tedavisi uygulanmış 23 hastanın verileri çalışmaya dahil edildi. Ortalama takip süresi $806( \pm 496.04)$ gün oldu. Dokuz hasta tedavisinde $8 \mathrm{~F}$ kateter, 14 hasta tedavisinde $14 \mathrm{~F}$ kateter kullanıldı. Tedavi etkinliği $8 \mathrm{~F}$ kateter grubunda \% 88.8, $14 \mathrm{~F}$ kateter grubunda \% 92.8 olmuştur. Lokal rekürrens her iki grupta da birer adet gelişti. Tedavi etkinliği, komplikasyon ve lokal rekürrens açısından her iki grup arasında anlamlı fark saptanmadı (sırasıyla $\mathrm{p}=0.742, \mathrm{p}=0.668, \mathrm{p}=0.640$ ). $8 \mathrm{~F}$ ve $14 \mathrm{~F}$ kateter kullanılan gruplar arasında hastanede yatış süresi açısından istatiksel olarak anlamlı farklılık saptanmadı ( $\mathrm{p}=1.000) .8 \mathrm{~F}$ ve $14 \mathrm{~F}$ kateter kullanılan gruplar arasında kateterizasyon süresi $8 \mathrm{~F}$ kateter kullananlarda daha kısa oldu ( $\mathrm{p}=0.046)$.

Sonuç: CE2 tipi karaciğer kist hidatik tedavisinde modifiye kateterizasyon yönteminde $14 \mathrm{~F}$ kateterler gibi $8 \mathrm{~F}$ kateterlerin de kullanımı etkin ve güvenlidir.

Anahtar kelimeler: kist hidatik, karaciğer, modifiye kateterizasyon yöntemi, echinococcus granulosus

DOI: 10.5798/dicletip.755757

Correspondence / Yazışma Adresi: Bekir Turgut, Konya Eğitim ve Araştırma Hastanesi, Sağllk Bilimleri Üniversitesi, Radyoloji ABD, Konya, Türkiye email:drbekirturgut@gmail.com 


\title{
The Comparison Of The Use Of 8-F And 14-F Catheters In The Treatment Of Type CE2 Hepatic Hydatid Cyst Lesions With The Modified Catheterization Technique
}

\begin{abstract}
Objective: In this study, we aimed to compare the selection of catheter thickness in terms of efficacy, recurrence, complication and length of hospital stay in the modified catheterization technique used in the treatment of CE2 hepatic hydatid cysts.

Method: The data of the patients diagnosed with CE2 hepatic hydatid cysts and undergoing modified catheterization treatment between January 2016 and January 2020 were reviewed retrospectively. The patients in whom 8-F and 14-F catheters were used in the modified catheterization technique were listed. Cyst type, cyst size and localization were listed by an interventional radiologist after scanning pre-treatment ultrasound reports. The recorded percutaneous treatment information and reports were evaluated, and the type of treatment applied, thickness of catheter used, complications, duration of catheterization and length of hospital stay were listed. Follow-up period, cyst size at the last follow-up, long-term recurrence results and recurrence treatment methods were recorded using the follow-up ultrasound reports. These listed variables were compared statistically in both groups.
\end{abstract}

Results: The data of 23 patients who underwent modified catheterization treatment due to type CE2 hydatid cysts were included in the study. The mean follow-up was $806( \pm 496.04)$ days. 8-F catheters were used in the treatment of 9 patients, and 14-F catheters were used in the treatment of 14 patients. The efficacy of the treatment was at the rate of $88.8 \%$ in the 8 -F catheter group and $92.8 \%$ in the 14-F catheter group. One local recurrence developed in both groups. No significant difference was found between the two groups in terms of treatment efficacy, complications and local recurrence $(p=0.742, p=0.668, p=0.640$, respectively). There was no statistically significant difference between the groups in which 8-F and 14-F catheters were used in terms of length of hospital stay (p $=1.000)$. The duration of catheterization was shorter in the $8-\mathrm{F}$ catheter group compared to the $14-\mathrm{F}$ catheter group $(\mathrm{p}=0.046)$.

Conclusion: 8-F catheters can be used effectively and safely like 14-F catheters in the modified catheterization technique in the treatment of CE2 type hepatic hydatid cysts.

Keywords: hydatid cyst, liver, modified catheterization method, echinococcus granulosus

\section{GíRiş}

Kist hidatik Echinococcus granulosusun neden olduğu bir hastalıktır ve toplumu etkileyen önemli bir halk sağlığı sorunudur1. Kist hidatik ülkemizi de içeren Akdeniz ve Ortadoğu ülkelerinde endemiktir ${ }^{2}$. Parazitin en slk etkilediği ve hastalık oluşturduğu organ karaciğerdir ${ }^{3,4}$.

Kistik ekinokokuz(CE) kistleri Dünya Sağlık Örgütü sinıflandırılmasına göre aktif (CE1, CE2), geçiş/transizyonel (CE3a ve CE3b) ve inaktif (CE4, CE5) formlarda evrelendirilir ${ }^{5}$. CE1, CE2 ve CE3 karaciğer kist hidatiklerinin tedavi edilmesi önerilmektedir6.

Hepatik kist hidatik tedavisi için kemoterapi, cerrahi ve perkütan drenaj olmak üzere üç terapötik yöntem vardır ${ }^{7}$. Karaciğer kist hidatik hastalığ minimal invaziv ve yüksek teknik başarı oranı nedeni ile son ylllarda daha çok tercih edilir hale geldi8,9.Özellikle CE2 karaciğer kist hidatiklerinin tedavisinde modifiye kateterizasyon tekniği (MoCAT) cerrahi tedaviye önemli bir alternatif yöntem oldu. $\mathrm{Bu}$ yöntemde genellikle $14 \mathrm{~F}$ gibi kalın kateterler önerilmektedir ${ }^{10}$.

Bu çalışmada MoCAT yöntemi ile tedavi edilen CE2 kist hidatik hasta grubunda kateter kalınlık seçiminin, etkinlik, rekürrens, komplikasyon ve hastane yatış süresi açısından karşılaştırılması amaçlandi.

\section{YÖNTEMLER}

Çalışmadaki tüm prosedürler insan katılımcılara, ulusal araştırma komitesi standartlarına ve 1964 Helsinki Deklarasyonu ve sonraki baskılarına ilişkin etik kurallara uygun olarak yapılmıştır. Bu çalışma yerel etik kurulu tarafından onaylandı (etik kurul karar yilı ve sayısı: 2020/007).

\section{Çalışma Planı ve Hasta Seçim Kriterleri}

Ocak 2016 ve Ocak 2020 tarihleri arasında, karaciğer kist hidatik perkütan tedavi 
uygulanmış hastaların kurumda bulunan perkütan tedavi öncesi USG, perkütan tedavi ve tedavi sonrası yatış dosyaları incelendi. Girişimsel radyolog tarafından ön değerlendirme amaçlı uygulanmış olan ultrasonografi (USG) raporları değerlendirildi. CE2 karaciğer kist hidatik tanıl ve MoCAT tedavi uygulanmış olan hastaların verileri incelendi.

Yaş ve cinsiyet bilgileri kayıt edildi. Girişimsel radyoloji uzmanı tarafından tedavi öncesinde yapılmış olan USG raporları taranarak kist tipi, kist boyutu ve lokalizasyonu listelendi. Kist hidatik tipi sınıflandırılmasında Dünya Sağlık Örgütü tarafından yayınlanmış olan CE kriterleri kullanıldı ${ }^{5}$ (Tablo I). Kayıtlı olan perkütan tedavi bilgileri ve raporları değerlendirilerek uygulanan tedavi türü, kullanılan kateter kalınlığı, komplikasyonlar, kateterizasyon süresi, hastanede yatış süresi listelendi. Takip USG raporları değerlendirilerek takip süresi, kistin son kontroldeki boyutu, uzun dönem nüks sonuçları ve nüks tedavi yöntemleri kayıt edildi.

Tablo I: Dünya Sağllk Örgütü ekinokokkozis çalışma grubu (WHO-IWGE) kist hidatik sınıflandırılması .

\begin{tabular}{|l|l|}
\hline CL & $\begin{array}{l}\text { Yuvarlak ya da ovoid şekilli, uniloküler, anekoik yapıda, ayrı } \\
\text { bir duvar yapısı seçilemeyen kistik lezyon. }\end{array}$ \\
\hline CE1 & $\begin{array}{l}\text { Yuvarlak veya ovoid şekilli, uniloküler, anekoik yapıda veya } \\
\text { hidatik kum bileşeni bulunabilen, duvarı seçilebilen kistik } \\
\text { lezyon. Duvarının seçilebilmesi ve hidatik kum varlığı } \\
\text { patognomoniktir. }\end{array}$ \\
\hline CE2 & $\begin{array}{l}\text { Yuvarlak veya ovoid şekilli, araba tekerleği veya balpeteği } \\
\text { görünümü oluşturan multiveziküler, multiseptalı, duvarı } \\
\text { seçilebilen kistik lezyon. Kız kistler ana kistin içini tamamen } \\
\text { ya da kısmen doldurabilir. }\end{array}$ \\
\hline CE3 & $\begin{array}{l}\text { Bu kistler ultrasonografide kompleks kitle şeklinde izlenirler. } \\
\text { Kist dejenerasyonu başlamış olup geçiş evresindedir. Ancak } \\
\text { halen kız kist oluşabilmektedir. İki alt tipi vardır; }\end{array}$ \\
CE3a & $\begin{array}{l}\text { Kist duvarından ayrılmış yüzen membranların izlendiği } \\
\text { nilüfer çiçeği bulgusu) anekoik kistik lezyon, }\end{array}$ \\
\hline
\end{tabular}

\begin{tabular}{|l|l|}
\hline CE3b & $\begin{array}{l}\text { Kız kist ve ekojenik alanları (ayrışmış membran / dejenere kız } \\
\text { kistler) olan, uniloküler kistik lezyon. }\end{array}$ \\
\hline CE4 & $\begin{array}{l}\text { Heterojen hipoekoik veya hiperekoik dejeneratif içerikli ve } \\
\text { izlenebildiği lezyon. Kız kistler yoktur. İnaktif evre olup } \\
\text { genellikle fertil değildir. }\end{array}$ \\
\hline CE5 & $\begin{array}{l}\text { Kalın kemer şeklinde kalsifiye duvarı ve bu duvarın neden } \\
\text { Kalduğu yoğun posterior akustik gölgesi olan lezyon. } \\
\text { genellikle fertil değildir. }\end{array}$ \\
\hline
\end{tabular}

1.3.6.9.12.24.36.48.60. aylarda girişimsel radyolog tarafindan yapılan USG takiplerinde inaktivasyon sürecini değerlendirme amaçlı şu kriterler dikkate alındı. Boyut ve içeriğinde herhangi bir değişiklik olmayan kist, iç membran yapısı bozulmamış pür kistik görünüm olanlar yetersiz tedavi olarak değerlendirildi. İçerisinde yeni kız vezikül görülmesi nüks olarak değerlendirildi.

\section{İstatiksel Analiz}

Araştırma verileri "SPSS (Statistical Package for Social Sciences) for Windows 22.0 (SPSS Inc, Chicago, IL)" aracılığıyla bilgisayar ortamına yüklendi ve değerlendirildi. Tanımlayıcı istatistikler ortalama, standart sapma değerleri ve yüzde olarak sunuldu. Kategorik değişkenlerin değerlendirmesinde Fisher's exact Testi kullanıldı. Nicel değişkenlerin normal dağılıma uygunluğu görsel (histogram ve olasılık grafikleri) ve analitik yöntemler (Kolmogorov-Smirnov/Shapiro-Wilk Testi) kullanılarak incelendi. Normal dağılıma uymadığı saptanan değişkenler için; iki bağımsız grup arasındaki istatistiksel anlamlllıklarda Mann-Whitney U Testi istatistiksel yöntem olarak kullanıldı. İstatistiksel anlamlılık düzeyi $\mathrm{p}<0.05$ olarak kabul edildi.

\section{Perkütan Tedavi Öncesi Değerlendirme}

Tedaviyi uygulayacak olan girişimsel radyolog tarafindan, tedavi öncesinde hastadan 
laboratuvar tahlilleri elde edildi ve USG uygulandı. Tam kan sayımı, protrombin ve parsiyel tromboplastin süreleri, uluslararası normalleştirilmiş oran (INR) ve trombosit sayısı belirlendi. INR $<1.5$ ve trombosit sayısı > 100.000 / ml olanlar perkütan tedaviye uygun kabul edildi. İkincil yayılma riskini azaltmak için profilaksi amaçlı olarak perkütan tedaviden 10 gün önce $10 \mathrm{mg} / \mathrm{kg} /$ gün dozunda oral Albendazol verildi ve tedaviden 15 gün sonrasına kadar devam edildi.

\section{Perkütan Tedavi ve Takip Prosedürleri}

Tüm tedavi basamakları USG ve floroskopi klavuzluğu altında yapıldı. USG kılavuzluğunda $18 \mathrm{G} 15 \mathrm{~cm}$ iğne ile kist içerisine transhepatik yaklaşım ile girildi. Sonrasında kist basıncını azaltmak amaçlı 40-50 cc kadar kist içi sıvı boşaltıldı. Kist boşluğuna iğne içerisinden $10 \mathrm{cc}$ kontrast madde enjekte edildi floroskopi ile kist görünürlügü artırıldı. $0.03575 \mathrm{~cm}$ sertklavuz tel kist içerisine gönderildi. İğne tel üzerinden geri alınarak uygun dilatörler ile yol dilatasyonu uygulandı. Sonrasinda $8 \mathrm{~F}$ veya $14 \mathrm{~F}$ pigtail kateter (Bioteq, Taipei, Taiwan veya Flexima, Boston Scientific, USA) kılavuz tel üzerinde ilerletildi ve kist kavitesinin içerisine yerleştirildi. Sonrasında kist normal hacminim üçte ikisi kadar hacimde skolosidal (\%30 hipertonik salin) madde enjekte edildi ve 10 dakika beklenildi. Sonra içerik aspire edildi. Devamında 20 ml'lik bir şırınga ile kaviteye izotonik salin $(\mathrm{NaCl} \% 0,9)$ enjekte edildi ve aynı miktar hemen aspire edildi. MoCAT tekniğinde eş zamanlı olarak aspirasyon ve kist içeriği berrak gelinceye kadar izotonik salin ile yıkama uygulandı. Enjeksiyon ve aspirasyon hareketi bazı kist membran parçalarını aspire etmemizi ve küçük vezikülleri parçalamamızı sağladı. Bu eylem, tüm kist içeriğini boşaltana kadar tekrarlandı. İlk gün boşaltım tamamen sağlanamazsa, ertesi gün aynı işlem tekrarlandı. Sonrasında kateter ucuna torba bağlandı ve serbest drenaja bırakıldı. Kateter çıkarıldıktan bir gün sonra taburcu edildi. 1.-3.-6.-9.-12.-24.36.-48.-60. aylarda USG ile takip kontrolleri uygulandı.

\section{BULGULAR}

CE2 tipi kist hidatik nedeni ile MoCAT tedavisi uygulanmış 3 ile 67 yaş arasında 23 hastanın verileri çalışmaya dahil edildi. Hastaların ortalama yaşı $38.70 \quad( \pm 20.33)$ olmuştur. Karaciğerde kist yerleșiminin \%26'sı kc sağ lobda, \%74'ü sol lobda oldu. Ortalama kist boyutu $7.04( \pm 2.77) \mathrm{cm}$ oldu. Tedavi etkinlik oranı \%91olarak bulundu. Dokuz hasta tedavisinde kateter $8 \mathrm{~F}$ kateter, 14 hasta tedavisinde $14 \mathrm{~F}$ kateter kullanıldı. $8 \mathrm{~F}$ ile tedavi edilen hastalarda tedavi etkinliği \%88,8, $14 \mathrm{~F}$ kateter kullanılan hastalarda tedavi etkinliği \% 92.8 olmuştur. Tedavi etkinliği ve nüks açısından her iki grup arasında anlamlı fark saptanmadı $(\mathrm{p}=0.742)$. Son takip kist boyutu $5.35( \pm 1.93) \mathrm{cm}$ oldu. Ortalama takip süresi 806 $( \pm 496.04)$ gün oldu. Toplamda beş hastanın takipleri kayıtlarda görülmedi. Takip kayıp oranımız \%21,7 oldu.

Genel ortalama hastanede yatış süresi 2.65 $( \pm 1.49)$ gün ve kateterizasyon süresi $2.39( \pm 1.77)$ gün olmuştur. Ortalama hastanede yatış süresi $8 \mathrm{~F}$ kullanılan grupta $2,56( \pm 1,13)$ ve $14 \mathrm{~F}$ kateter kullanılan grupta $2,71( \pm 1,72)$ gün olmuştur. $8 \mathrm{~F}$ ve $14 \mathrm{~F}$ kateter kullanılan gruplar arasında hastanede yatış süresi açısından istatiksel olarak anlamlı farklılık saptanmadı ( $\mathrm{p}=1)$.Ortalama kateterizasyon süresi $8 \mathrm{~F}$ kullanılan grupta $1,78( \pm 1,56)$ ve $14 \mathrm{~F}$ kateter kullanılan grupta $2,79( \pm 1,84)$ gün olmuştur. $8 \mathrm{~F}$ ve $14 \mathrm{~F}$ kateter kullanılan gruplar arasında kateterizasyon süresi $8 \mathrm{~F}$ kateter kullananlarda süre daha kısa oldu ( $\mathrm{p}=0.046)$.

Toplamda üç (\%13) hastada periprosedüral minör komplikasyon gelişti. Periprosedüral major komplikasyon görülmedi. $8 \mathrm{~F}$ kateter grubunda $1(\% 11,1)$ hastada ateş minör komplikasyonu görüldü. $14 \quad \mathrm{~F}$ kateter kullanılanlarda ateş ve geçici kist içi kanama 
olmak üzere 2 (\%14,3) hastada minör komplikasyon görüldü. Komplikasyon sıklığı açısından her iki grup arasında istatiksel anlamlı farklılık saptanmadı ( $\mathrm{p}=0.668)$.

$8 \mathrm{~F}$ kateter grubunda 1(\%11.1) hastada, $14 \mathrm{~F}$ kateter kullanılanlarda $1(\% 7,1)$ hastada lokal rekürrens oldu. Lokal rekürrens siklığ açısından her iki grup arasında istatiksel anlamlı farklılık saptanmadı $(\mathrm{p}=0.640)$. Bir hastada 9. ay kontrolde lokal rekürrens gelişti ve ikinci defa perkütan tedavi uygulandı. Aynı hastada 24. Ay kontrolünde ikince kez lokal rekürrens gözlendi. Bu aşamadan sonra cerrahi tedaviye yönlendirildi. Başka bir hastada 3. ay kontrolde lokal rekürrens görüldü ve doğrudan cerrahi tedaviye yönlendirildi.

\section{TARTIŞMA}

$\mathrm{Bu}$ çalışmada MoCAT ile tedavi uygulanan karaciğer kist hidatiklerinde kateter kalınlığının tedaviye etkisi değerlendirildi. Her iki farklı kateter kullanımında da tedavi teknik başarı oranı $\% 100$ oldu. Uzun dönem takiplerde, $8 \mathrm{~F}$ ile tedavi edilen hastalarda tedavi etkinliği $\% 88,8$, $14 \mathrm{~F}$ kateter kullanılan hastalarda tedavi etkinliği \%92,8 olmuştur. Tedavi etkinliği ve nüks açısından her iki grup arasında anlamlı fark saptanmadi. Bu duruma ek olarak komplikasyon, hastanede yatış süresi açısından da her iki grup arasında istatiksel anlamlı fark bulunmadı. Sadece kateterizasyon süresinde istatiksel olarak anlamlı fark bulundu ve bu da 8 F kateter lehine oldu. Sadece $14 \mathrm{~F}$ kalınlığındak ikateterlerin değil $8 \mathrm{~F}$ kalınlıktaki kateterlerin de MoCAT tedavisinde güvenle kullanılabileceği bilgisi kanitlandı.

CE 2 karaciğer kist hidatik tedavisinde cerrahi tedavi veya MoCAT tekniği ile perkütan tedavi önerilmektedir ${ }^{11}$. Küçük boyutlu kistlerde, asemptomatik olanlarda ve genel performansı düşük olan hastalarda cerrahi tedavi önerilmemektedir ${ }^{12}$. Cerrahi tedavi temel küratif yaklaşımdır, fakat cerrahi girişim sonrası morbidite $\% 32$, mortalite $\% 0,5-8$ ve rekürrens oranı da $\% 20^{\prime}$ lere ulaşabiliri ${ }^{13}$.

MoCAT tekniği ilk olarak Saremi tarafından 1992'de tarif edilmiştir'14. Tariflediği yöntemde kistin perkütan yolla drenajının yanında germinatif membranın parçalanarak çıkarılması esasına dayanmaktadır. Kist sıvısının aspire edilmesine karşın; yerinde bırakılan germinatif membranın taşıdığı nüks potansiyeli olduğu görüşleride öne sürülmüştür15. Fakat bu görüşün aksine CE2 ve $3 \mathrm{~b}$ için modifiye perkütan tedavi teknikleri son otuz yıldır tanımlanmıştır ve çalışmalar bizimki gibi düşük nüks oranları bildirmiştir ${ }^{16-18}$.

Kahriman ve arkadaşları yakın dönemde ortalama takip süresi 18 ay olan bir makale yayınladılar. Tüm CE2 ve $10 \mathrm{~cm}$ üstünde boyutu olan CE1 karaciğer kist hidatik lezyonlarınada MoCAT tedavi yöntemi uygulamışlardır. Skolosidal ajan olarak \%30 hipertoniksalin ve sklerozan ajan olarak \%95 etil alkol kullanmışlarır ${ }^{19}$. Bu çalışma bizim çalışmamıza literatürde en çok benzeyen çalışmadır. Ancak bazı farklar mevcuttur. Çalışmalarında ortalama takip süreleri bizimkinden kısadır. Ek olarak MoCAT prosedürlerinde sadece $14 \mathrm{~F}$ veya $16 \mathrm{~F}$ kateter kullanmışlardır. Bu çalışmada farklı olarak $8 \mathrm{~F}$ ve $14 \mathrm{~F}$ iki farklı kalınlıktaki kateterlerin sonuçları karşılaştırıldı. MoCAT yönteminin daha küçük kalınlıktaki kateterler ile de yapılabileceği görüşü ortaya konuldu. Şöyle ki, MoCATyöntemi kız vezikülleri parçalanması, germinatif membranın parçalanması ve dışarı alınması prensiplerine dayanmaktadır. Bizim görüşümüze göre burada başarıyı etkileyebiecek iki ayrı faktör vardır. Birincisi; tüm kız vezikülleri parçalanması, kist içerisindeki skolekslerin skolosidal ajanlar ile inaktivasyonudur. İkincisi ise kist iç yapısının ve parçalanmış membranların tamamının dişarı alınmasıdır. Kist içeriğinin tamamının dışarı alınması için kalın ve geniş delikli kateter kullanılması gerektiği belirtilmektedir ${ }^{20}$. Eğer tedavideki asıl etkinlik kız veziküllerinin 
parçalanması skolosidal ve sklerozan ajanlar ile kist inaktivasyonu ve dejenerasyonu ise bu kadar kalın kateter kullanılmadan da tedavi edilebilir. Örneğin PAİR (puncture, aspiration, injeksion, reaspiration) ve standart kateterizasyon yöntemlerinde kist içindeki dejenere olmuş, çökmüş membranöz ve diğer dejeneratif yapılar vücut dışına aspire edilemez. $\mathrm{Bu}$ yapılar vücut dışına alınmadığı halde etkin oldukları kanıtlanmış bir gerçektir ${ }^{21}$. PAİR ve standart kateterizasyon yönteminde de yapıldığı gibi kist içi solid yapıların tamamının alınmasının etkinlik açısından temel unsur olmayabileceğini düşünüyoruz. Şöyle ki, MoCATyönteminde bile bazı hastalarda kist içeriğini tamamen alamamaktayız. Parçalanmış membranöz kist içeriğinin orada olması nüks sebebi olsa idi bu hastaların hepsinde nüks olması gerekirdi. Sonuçlarımızda belirttiğimiz gibi bu çalışmada $8 \mathrm{~F}$ kateter kullanımında da skolidal ajan ve kistobilier fistül yok ise sklerozan ajan uygulaması yaptık. Ayrıca bu tedavilerde $14 \mathrm{~F}$ kateterde uyguladığımız ile aynı olarak septa ve kız veziküllerinin parçalanması amaçlı serum fizyolojik sıvı ile ver-çek şeklinde irrigasyon yapıldı. Ek olarak kateterin kist içerisinde kendi ekseni etrafında döndürerek aspirasyon manevraları uygulandı. Nitekim uzun dönem sonuçlarımızda tedavi etkinliği ve rekürrens açısından her iki grup arasinda anlamlı fark saptanmadı. $8 \mathrm{~F}$ kateter kullanılan hastalarda hastanede yatış süresi daha kısa olmuştur. Fakat bu durum istatiksel olarak anlamlı bulunmadı. 8F kateter kullananlarda kateterizasyon süresi istatiksel olarak daha kısa oldu. Komplikasyon sıklığ açısından da her iki grup arasında istatiksel anlamlı farklılık saptanmadı. Bu çalışma CE2 kist tedavisinde MoCAT yönteminde farklı kalınlıkta kateterleri her yönü ile karşılaştıran ve değerlendiren ilk çalışma oldu. $14 \mathrm{~F}$ kateter 8 F'e kıyasla belirgin kalındır. Bu sebeple kateterin geçtiği karaciğer yolunda daha fazla karaciğer dokusunda tahribata yol açar ve işlem sonrası hastada daha fazla ağrıya sebep olabilir.
Bu nedenle tedavi etkinliği benzer olan iki farklı kalınlıktaki kateterin ince olanının seçilmesinin daha uygun olabileceği düşüncesindeyiz.

Çalışmamızda bazı kısıtlıklar mevcuttu. Birincisi; retropektif bir çalışmanın doğasında bulunan kısıtlılıkları içermektedir. İkincisi; okuyucu tarafından hasta sayımızın daha çok olması beklenebilir. Fakat kist hidatik tek bir tipinin tek bir tedavi yöntemi konu olduğu için hasta sayısının az olması doğal olarak değerlendirilmelidir.

Sonuç olarak MoCAT yöntemi ile CE2 grubu karaciğer kist hidatik tedavisinde $14 \mathrm{~F}$ kateterler gibi $8 \mathrm{~F}$ kateterlerinde kullanımı etkin ve güvenlidir.

Etik Kurul Kararı: Çalışmadaki tüm prosedürler insan katılımcılara, ulusal araștırma komitesi standartlarına ve 1964 Helsinki Deklarasyonu ve sonraki baskılarına ilişkin etik kurallara uygun olarak yapılmıştır. $\mathrm{Bu}$ çalışma yerel etik kurulu tarafından onaylandı (etik kurul karar yılı ve sayısı : 2020/007).

Çıkar Çatışması Beyanı: Yazarlar çıkar çatışması olmadığını bildirmişlerdir.

Finansal Destek: Bu çalışma her hangi bir fon tarafından desteklenmemiştir.

Declaration of Conflicting Interests: The authors declare that they have no conflict of interest.

Financial Disclosure: No financial support was received.

\section{KAYNAKLAR}

1. Özgür T, Kaya ÖA, Hakverdi S, ve ark. Ekinokokkozis olgularının histopatolojik yönden retrospektif olarak değerlendirilmesi. Dicle Medi J. 2013; 40: 641-4.

2. Şahin E. M, Yüksek Y. N, Dağlar G, Gözalan U, Kama N. A. Diagnosis and treatment of hydatid cysts: Results of 120 patients. Trakya Univ Tip Fak Derg. 2008; 25: 6-14. 
3. Turgut AT, Akhan O, Bhatt S, Dogra VS. Sonographic spectrum of hydatid disease. Ultrasound Quarterly. 2008; 24: 17-29.

4. Piskin T, Ara C, Dirican A, et al. Perforated hydatid cyst into peritoneum presented with urticaria: A casereport. Dicle Med J. 2010; 37: 71-4.

5. WHO Informal Working Group. International classification of ultrasound images in cystic echinococcosis for application in clinical and field epidemiological settings. Acta Trop. 2003; 85: 253-61.

6. Bhutani N, Kajal P. Hepatic echinococcosis: A review. Ann Med Surg (Lond). 2018; 36: 99-105.

7. Smego RA Jr, Sebanego P. Treatment options for hepatic cystic echinococcosis. Int J Infect Dis. 2005; 9: 69-76.

8. Kabaalioğlu A, Ceken K, Alimoglu E, Apaydin A. Percutaneous imaging-guided treatment of hydatid liver cysts: Do long-term results make it a first choice? European Journal of Radiology. 2006; 59: 65-73.

9. Giorgio A, de Stefano G, Esposito V, et al. Long term results of percutaneous treatment of hydatid liver cysts: a single center 17 years experience. Infection. 2008; 36: 256-61.

10. Popa AC, Akhan O, Petruţescu MS, et al. New options in the management of cystic echinococcosis - A single centre experience using minimally invasive techniques. Chirurgia (Bucur). 2018; 113: 486-96.

11. Wen $H$, Vuitton $L$, Tuxun $T$, et al. Echinococcosis: Advances in the 21st Century. Clin Microbiol Rev. 2019; 32: pii: e00075-18.

12. Çaycı M, Tihan D. Karaciğer kist hidatik tedavisinde güncel yaklaşım. Uludağ Üniversitesi Tıp Fakültesi Dergisi. 2016; 42: 539.

13. Daradkeh S, El-Muhtaseb H, Farah G, Sroujieh AS, AbuKhalaf M. Predictors of morbidity and mortality in the surgical management of hydatid cyst of the liver. Langenbecks Arch Surg. 2007; 392: 35-9.

14. Saremi F. Percutaneous drainage of hydatid cysts: use of a new cutting device to avoid leakage. Am J Roentgenol. 1992;158: 83-6.

15. Yetim İ, Erzurumlu K. Karaciğer hidatik kistleri tedavisinde güncel yaklaşımlar. J Clin Anal Med. 2013; 4: 64-71.

16. Haddad MC, Sammak BM, Al-Karawi M. Percutaneous treatment of heterogenous predominantly solid ech pattern echinococcal cysts of the liver. Cardiovasc Intervent Radiol. 2000; 23: 121-5.

17. Gabal AM, Khawaja FI, Mohammad GA. Modified PAIR technique for percutaneous treatment of high risk hydatid cysts. Cardiovasc Intervent Radiol.2005; 28: 200-8.

18. Schipper HG, Lameris JS, vanDelden OM, Rauws EA, Kager PA. Percutaneous evacuation (PEVAC) of multivesicular echinococcal cysts with or without cystobiliary fistulas which contain non-drainable material: first results of a modified PAIR method. Gut. 2002; 50: 718-23.

19. Kahriman G, Ozcan N, Dogan S, Karaborklu O. Percutaneous treatment of liver hydatid cysts in 190 patients: a retrospective study. ActaRadiol. 2017; 58: 676-84.

20. Akhan O, Gumus B, Akinci D, Karcaaltıncaba M, Ozmen M. Diagnosis and percutaneous treatment of soft tissue hydatid cysts. Cardiovasc Intervent Radiol. 2007; 30: 419-25.

21. Turan HG, Özdemir M, Acu R, et al. Comparison of seldinger and trocar techniques in the percutaneous treatment of hydatid cysts. World J Radiol. 2017; 9: 405-12. 